\title{
The evaluation of Edible Bird Nest (EBN) Extract Reduced Influenza A virus Induced Apoptosis on Cultured Cells in vitro study
}

\author{
Nur Ain Aminuddin ${ }^{1 *}$, Amin Haghani ${ }^{2}$, Nikoo Safi², Abdul Rahman Omar ${ }^{1,3}$ and Aini Ideris ${ }^{1,3}$ \\ ${ }^{1}$ Institute of Bioscience, Universiti Putra Malaysia, 43400 Serdang, Selangor, Malaysia \\ ${ }^{2}$ Davis School of Gerontology, University of Southern California, Los Angeles, California, USA \\ ${ }^{3}$ Faculty of Veterinary Medicine, Universiti Putra Malaysia, 43400 Serdang, Selangor, Malaysia.
}

Received: 27 September, 2016; Accepted: 03 October, 2016; Published: 13 October, 2016

*Corresponding author: Nur Ain Aminuddin, Institute of Bioscience, Universiti Putra Malaysia, 43400 Serdang, Selangor, Malaysia; E-mail: ainamin2013@gmail.com

\begin{abstract}
Edible bird nest (EBN) mainly comprises a secretion of the salivary gland of different Swiftlet species has been used as a symbol of wealth and power as well as an crucial ingredient in traditional Chinese Medicine. The MTT assay and flow cytometry analysis were carried out to evaluate the effect of EBN extract in treated Influenza A virus infected MDCK cells. MTT assay was performed to determine the cell viability and Ha assay was used to determine the virus titer after 24 hour of post treatment with EBN extract towards MDCK cells challenged with influenza A virus. The results showed that there was a significant increase in cell viability $(p<0.05)$ of EBN extract treatment compared to positive infected control. Annexin V-fitc double staining method was carried out to identify the mode of cell death in MDCK cells by calculating the means of each apoptosis stage. The results showed that there was a significant reduced early apoptotic injury in infected cells treated with EBN extract. In summary, the current finding suggests that EBN may be have the potentiality to be as an apoptotic inhibitor and ameliorate the infected cells caused by virus.
\end{abstract}

Keywords: Influenza A virus; Apoptosis; Edible Bird Nest; MTT assay; Flow Cytometry

\section{Introduction}

Apoptosis is an important physiological necessary for development and maintenance of tissues homeostasis including tissue atrophy, the immune system development and biological tumor [1-2]. It also plays an important function in the pathogenesis of many infectious diseases including those caused by viruses [3-5]. Many virus infections result in apoptosis of host cells, and several viruses have evolved mechanisms to inhibit apoptosis. Influenza viruses induce apoptosis through mechanism then both cellular and viral factors depending on the cell type. However, the precise mechanism still remain unclear.

Edible bird nest (EBN) is natural food product made from Aerodramus genus Swiftlet's saliva. Studies show its unique glycoprotein properties provide health benefits, cure many illnesses and rejuvenate cells. The nests contain almost all of the bessential ingredients for body maintenance. Amino acids, minerals, and others keep the body healthy and increase immunity against a host of illness. Another studies have shown that this animal saliva previously found to contain bioactive compounds that are powered with anti-apoptotic and antioxidant properties [6-7]. As apoptosis have been suggested as crucial events in Influenza virus infection, EBN, the salivary secretion of swiftlets, may have anti-apoptosis relevance in the therapeutic context of viral infection. Hence, this study aimed to investigate the anti-apoptosis effect of EBN.

\section{Materials and Methods}

\section{Preparation of EBN Extracts}

Raw EBN from the swiftlet of Aerodramus genus collected from bird's nest house in Teluk Intan, Perak, Malaysia. The cleaning process was carried out by first soaking after the unprocessed EBN in distilled water until softened. Debris and feathers were removed after which the EBN was subjected to drying process at $70^{\circ} \mathrm{C}$ for $16 \mathrm{hrs}$ and followed by grounding and sifting through a mesh $(60 \mu \mathrm{M}$ in pore size). The grounded samples were kept in distilled water at $3^{\circ} \mathrm{C}$ in about 16 hours and continued heated for $30-60 \mathrm{~min}$ at $60^{\circ} \mathrm{C}$. The extract was then filtered and freeze-dried after 48 hours freezing at $-80^{\circ} \mathrm{C}$, and stored for the following experiment.

\section{Madin Darby Canine Kidney (Mdck) Cell Culture}

MDCK cell line was purchased from the American Type Culture Collection (ATCC,CCL-34 ${ }^{\mathrm{TM}}$ ) and grown in Dulbecco's Modified Eagle's Medium (Gibco,UK) supplemented with $10 \%$ fetal bovine serum (Gibco, UK), antibiotic-antimycotic (Gibco,UK). The cells then were seeded into a sterile 96-well flat bottom plate (Nunc, USA) and maintained at $37^{\circ} \mathrm{C}$ humidified incubator with $5 \% \mathrm{CO}_{2}$ (Galaxy, UK) for 2-3 days until 70\%-80\% confluency is achieved.

\section{Virus Propagation}

Influenza A virus, strain A/Puerto Rico/1934 (H1N1)was purchased from the American Type Culture Collection (ATCC, ( VR-95 ${ }^{\mathrm{TM}}$ ) and propagated in MDCK cells, then the stock virus was titrated by $\mathrm{TCID}_{50}$. In obtained $100 \mathrm{TCID}_{50}$, the resultant virus 
titer was further diluted with $100 \mu$ taken from the amount of $\mathrm{TCID}_{50}$ then it was to be used as a constant positive control in the following procedure.

\section{Cell Viability Based On Combination Treatment}

This procedure was performed by using Maximal NonCytotoxic Concentration of EBN and constant virus titer (100 TCID $_{50}$ ). Briefly,the virus was first inoculated into the MDCK cells and later followed by the EBN extract replacement for $1 \mathrm{hrs}$ followed by change with media. All the samples were incubated at $37^{\circ} \mathrm{C}$ in $5 \% \mathrm{CO}_{2}$ incubator.

After 24 hour of post-treatment incubation, the plates were exposed to the MTT assay. Treated cells were subjected to MTT reagent (Sigma Aldrich, USA) in which reacts to quantify the viable cells. Pure DMSO solution (Merck, Germany) was added to the cells after 2-3 hr exposure to the MTT reagent to solubilise the formazon precipitation. Absorbance of the solution was measured spectrophotomerically by using ELISA reader at 540nm wavelength (Bio Tek Instruments EL800,USA).

\section{Apoptotic Cells Analysis}

The protocol of Annexin V-FITC Apoptosis Detection Kit (BD Pharmingen, USA) by Rieger et al was performed in this procedure. Briefly, upon completion of treatments, cells were harvested and washed with binding buffer. Then, Annexin V and propidium iodide (PI) were added and incubated in dark for 15 min. Subsequently, washing was performed twice with binding buffer which then incubated for $15 \mathrm{~min}$ at $37^{\circ} \mathrm{C}$. Finally, the samples were reads for analysis with Becton Dickson FACS Calibur Flow Cytometer (BD Biosciences, USA).

\section{Statistical Analysis}

Data was collected as triplicate for each experiments. The results were expressed as mean \pm standard deviation. Statistical significance was assessed with Anova test and $P$ value $<0.05$ was considered significant.

\section{Result And Discussion}

\section{Cytotoxic Profile of Edible Bird Nest (EBN) Extract}

Toxicity study was first performed with addition of EBN extract to MDCK cells to determine the concentration side effect as well as MNCCs of the extract on cultured cells. MNCC is maximal non-cytotoxic concentration of the EBN extract.

Based on the [Figure 1], cytotoxicity percentage in MDCK cells showed an increasing trend of optimal density (OD) of cell viabilities along the concentration. As determined from the bar graph, MNCCs was $12.5 \mathrm{mg} / \mathrm{ml}$.

The EBN extract in water soluble form is likely less cytotoxic, thus same as previous report that pointed out the water soluble subtances possess less cytotoxic effect compared to the crude EBN extract. This is due to compound solubility and stability are major factors that contribute to varied activities in different extract [8] such as the application of high temperature during the water extraction process caused affected the potency of proteins within the EBN, possibility through denaturation [9].

\section{EBN extracts improves cell viability in H1N1 virus-} challeged MDCK cells

The MTT was performed in order to quantify the cell viability based on the apoptotic reduction activity. Upon challeged with $100 \mathrm{TCID}_{50 / \mathrm{ul}} \mathrm{HINI}$ virus for 24 hour post treatment with EBN extract, cell viability increased to about $20 \%$ of that of infected control [Figure 2]. Meawhile, the EBN alone treatment generally did not affect the infected group. This could be due to the mitogenic property of EBN that promoted cell growth, as made evident a study by Zainal Abidin et el. Which shows that EBN promoted cell divison in rabbit corneal keratocytes [10].

\section{EBN Extracts Reduce Early Apoptotic Event in H1N1 Virus Challeged MDCK Cells}

Apoptotic cells resulted due to phosphatidylserine (PS) translocation towards the outer leaflet of the plasma membrane caused the apoptotic or death cells and membrane integrity become loss. Therefore, the annexin V-FITC double stainig was performed in this study to calculate the percentage of cell death in different stages of apoptosis. In this assay, cells residing at different level of apoptosis upon exposure to the virus infection (A/Puerto Rico/8/1934 (H1N1)) by differential staining of DNA and also PS, whereby cells are grouped and revealed in dot plot. Annexin V-FITC-PI' (lower left quadrant) are classified as healthy cells, the cells that are considered early apoptotic showed Annexin V-FITC ${ }^{+} / \mathrm{PI}^{-}$(lower right quadrant), whereas late

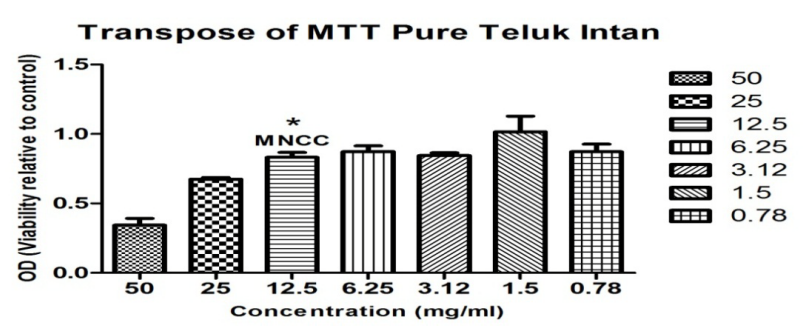

Figure 1: The MNCC value for EBN concentration. Asterisk (*) show the first non-significant difference of the cytotoxicity with with ( $\mathrm{p}<$ $0.05)$ cytotoxicity with $(\mathrm{p}<0.05)$ following Tukey HSD post hoc analysis.

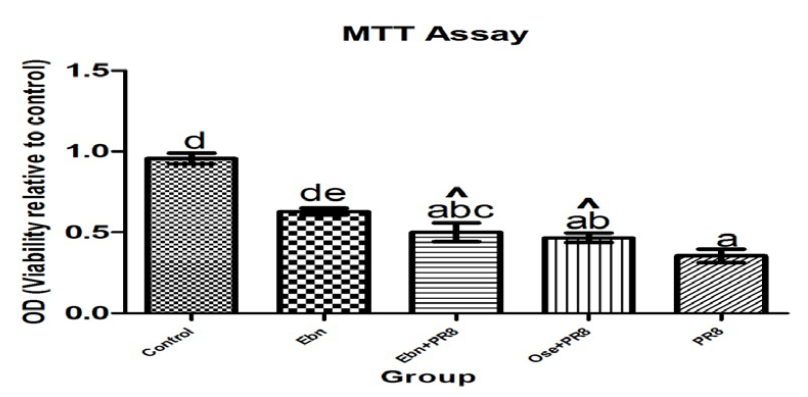

Figure 2: Effect of combination treatment on strain A/ Puerto Rico/8/1934 (H1N1)- challenged MDCK cell viability. Cell viability was assessed with MTT assay and data shown are means \pm SD by Tukey HSD pairwase comparison between groups $(\mathrm{p}<0.05)$. *abcde Values with different superscript differ significantly difference with infected group $($ PR8) $(\mathrm{p}<0.05)$ indicated by caret $(\wedge)$. 
apoptotic (upper right quadrant) represent as Annexin V-FITC ${ }^{+}$/ $\mathrm{PI}^{+}$as well as necrotic (upper left quadrant).

Based on the result, in general, EBN treatment MDCK cells [Figure 3B] alone did not stimulate apoptotic injury and also reduced the cell death population. Most of the infected MDCK cells-treated undergo significant in reduced apoptosis when compared to infected control [Figure 3A]. Meanwhile at 24 hour of post treatment, there was prominent significant reduced early apoptosis in EBN extract [Figure 3C] whilst reduced late apoptosis but less effectively compared to Oseltamivir treatment [Figure 3D].

\section{Conclusion}

It has been successfully demonstrated that EBN extracts confer apoptotic protection in H1N1-challenged MDCK cells. Particularly, EBN demonstrated apoptotic protection potential by improving cell viability. Thus, it can be concluded that EBN extracts shown to inhibit apoptosis.

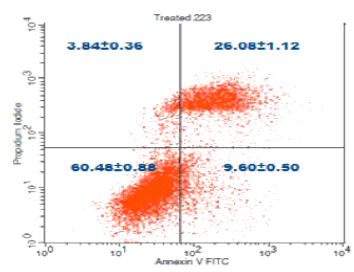

(A) Control PR8

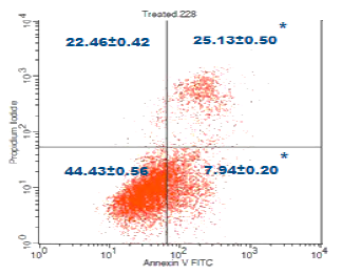

(C) $\mathrm{EBN}+\mathrm{PR8}$

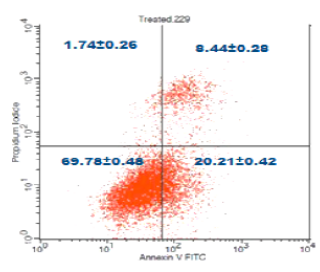

(B) EBN + MDCK Cells

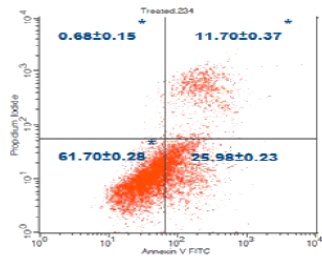

(D) OSE + PR8
Figure 2: Effect of EBN Extracts on H1N1-induced apoptosis in MDCK Cells: Cells treated with EBN extracts for 24 hours were analyzed by Annexin V-propodium iodide double staining. Representative plots of propidium iodide versus Annexin V-FITC fluorescence signals are shown (A-D). ${ }^{*} p<0.05$ versus H1N1 treated cells (control).

\section{Acknowledgement}

Our sincere gratitude to Dr Fadzillah A'ini, from Department of Veterinary Services, Putrajaya, Malaysia, who kindly provided EBN sample. This project was supported by Coe Swiftlet grants no.6371400 from Ministry of Agriculture,Putrajaya,Malaysia.

\section{References}

1. Jacobson MD, Weil M, Raff MC. Programmed cell death in animal development. Cell. 1997; 88(3):347-354.

2. Young LS, Dawson CW, Eliopoulos AG. Viruses and apoptosis. Br. Med. Bull. 1997;53(3):509-521.

3. Razvi ES, Welsh RM. Apoptosis in viral infections. Adv. Virus Res. $1995 ; 45: 1-60$

4. Ludwig S, Pleschka S, Wolff T. A fatal relationship influenza virus interactions with the host cell. Viral Immunol. 1999;12(3):175-196.

5. Roulston A, Marcellus RC, Branton PE. Viruses and apoptosis. Annu. Rev. Microbiol. 1999;53:577-628.

6. Mehraein F, Talebi R, Jameie B, Joghataie MT, Madjd Z. Neuroprotective effect of exogenous melatonin on dopamenergic neurons of the substantia nigra in ovariectomized rats. Iran Biomed J. 2011;5(12):44-50.

7. Falk T, Yue X, Zhang S, McCourt AD, Yee BJ, Gonzalez RT, et al. Vascular endothelial growth factor-B is neuroporotective in an vivo rat model of Parkinson's Disease. Neurosci Lett. 2011;496(1):43-47.

8. Lopes AP, Bagatela BS, Ros PC, Nanayakkara DN, Carlos Tavares Carvalho J, et al. Antioxidant and cytotoxic effects of crude extract, fractions, and 4-nerolidylcathecol from aerial parts of Pothomorphe umbellata L (Piperaceae). BioMed research international 2013, 2013:206581. doi: 10.1155/2013/206581.

9. Yew MY, Koh RY, Chye SM, Othman I, Ng KY. Edible bird nest ameliorates oxidative stress-induced apoptosis in SH-SY5Y human neuroblastoma cells. BMC Compliment Altern Med. 2014;14:391. doi: 10.1186/1472-6882-14-391.

10.Zainal Abidin F, Hui CK, Luan NS, Mohd Ramli ES, Hun LT, Abd Ghafar N.Effect of edible bird's nest (EBN) on cultured rabbit corneal keratocytes. BMC Complement Altern Med. 2011;11:94. doi: 10.1186/1472-6882-11-94. 